\title{
Enhancing Students' Reasoning Skills in Engineering and Technology through Game-Based Learning
}

\author{
https://doi.org/10.3991/ijet.v14i24.12117 \\ Corrienna Abdul Talib $(\bowtie)$ \\ Universiti Teknologi Malaysia, Johor, Malaysia. \\ corrienna@utm.my \\ Faruku Aliyu \\ Sokoto State University, Sokoto, Nigeria \\ Adi Maimun bin Abdul Malik, Kang Hooi Siang \\ Universiti Teknologi Malaysia, Johor, Malaysia
}

\begin{abstract}
Engineering and technology are crucial domains both in colleges and in the industries as they play a vital role in the nations' economy and serve as the medium for the nations' active participation in the global competitiveness aiming at attaining industrial revolution 4.0 goals. These goals are only realized when graduates, particularly engineers and technologist are equipped with reasoning skills. In view of this, the paper highlighted the connections between reasoning skills in technology and engineering through game-based learning. The paper utilized systematic review format and synthesized the existing literature through search strategy, inclusion and exclusion criteria, framework analysis and quality assessment. It further analyzed and discussed types of games in learning with relevant descriptions and how its integration into teaching and learning technology and engineering courses would enhance reasoning skills among students and promote their problem-solving ability and likewise creativity to innovate new products, machines and services for societal development. The paper suggested for the integrating of suitable games in learning technology and engineering courses.
\end{abstract}

Keywords - Game-based learning, Technology, Engineering, Reasoning Skills.

\section{Introduction}

Today's societal needs require students to learn in an educational environment that is expected to give them room to collaborate, critically think and analyze, individually and in a group, to develop innovative projects and products that would solve the problems or ease the difficulties in human lives. This learning environment is most particularly needed in disciplines such as technology and engineering that require the development of twenty-first centuries skills. Game-based learning is a learning environment that exposes students to varieties of skills and supports significant improve- 
ment in students' experience and achievement [1]. Recently there is a significant increase in computer games that are believed to be powerful tools for engaging students as a result of pleasure-driven from them [2]. The pleasure makes them be recognized as supporting tools for the learning environment that requires exploration, critical thinking and reasoning. According to Barata, Gama, Jorge, and Goncalves [2], although the use of games in learning is rare, it is however believed by both parent and teachers that computer games have potential ability to support and enhance valuable learning skills such as reasoning among the young learners.

This research article aimed at presenting connections between reasoning skills and learning engineering and technology course and discusses relevant games with supportive empirical studies to ascertain how game-based learning enhances reasoning skills in the said courses.

\section{$2 \quad$ Reasoning Skills in Technology and Engineering}

Many authors defined technology and engineering in different ways depending on the perspectives and the angle the two concepts were viewed. However, in whatever point they are viewed, it would be gathered that they are interrelated through the application of scientific and reasoning skills aimed at crafting and innovating products and services for the benefit of mankind. Technology and engineering are indispensable disciplines in human lives that involves the application of scientific knowledge and skills, and mathematical reasoning to innovate new system, devices, or products in order to solve technical problems and improve conditions for human lives [3-5]. These disciplines aimed at economically, using the forces and materials of nature, practicing and applying mathematical and science skills and experiences for simplifying and bettering the life of mankind. Both engineers and technologists are expected to design, innovate and develop new tools and products that simplify human life. They build and test new machines and repair them when they are faulty. One of the major reasons for the rapid growth and development of the developed nations compared to developing ones is their emphasis on technology and the engineering sector in an efforts to adjust to the rapid and developmental global changes and targets to attains goals sets for industrial revolution 4.0 [6]. These critical domains to nations' developments require a learning environment with hands-on activities to promote learners' reasoning skills to critically think and analyze the assembling of the basic components of a system/machine. In both technology and engineering, there are concepts that require project-based games to display mechanisms and constructions involved and enable technologist and engineers think, reason and solve problems associated with machines and products.

Lack of thinking and reasoning skills of assembling and disassembling relevant devices due to limited access to necessary equipment, projects and practices in school results to graduating of non-qualified and unprofessional technologists and engineers that could not assemble or disassemble a simple device not to talk of constructing a new one. Lack of reasoning skills for solving mechanical problems and designing innovative products is part of the major reasons why industries could not employ 
some graduate engineers even with available vacancies [7]. This scenario increases the rate of unemployment as some graduate engineers are not attractive and suitable for being less productive. Furthermore, Kaminska et al [7] outlined key challenges of technology and engineering professions in many developing countries. The challenges include; lack of standard teaching and learning facilities; and inappropriate learning strategies utilized by teachers. Most of the learning strategies utilized are not projectbased which are parts of what generated the present breach between the industries and the so-called graduate engineers and technologist that lack thinking and reasoning skills for designing innovative products. Hence preventing industries from absorbing them.

In addition, to join the global competition in realizing industrial revolution 4.0, technology and engineering sectors need to be strengthened to enhance designing and developing innovative services and products. According to Kojmane and Aboutajeddine [8], both technologist and engineers are expected to craft innovative product and services that would support nations to actively partake in the global competition of 21 st century requiring reasoning skills for analyzing and innovating products and services. Despite this requirement, many technologists and engineers were found poor in these skills and could not carry out simple designs and operations. Many students and graduates engineers are faced with a lot of challenges when it comes to innovating new design due to their low reasoning skills [8-10]. This problem of skills rendered them irrelevant.

Based on the empirical evidence on the effectiveness of the reasoning skills on engineering and technology domain as outlined above, one could deduce that reasoning skills in inevitable components of learning design, crafting and development of innovative products and services in technology and engineering domains. Students of technology and engineering courses are therefore expected to be taught using learning strategies such as game-based learning that can enhance their reasoning skills for effective performance.

\section{Game-Based Learning and the Reasoning Skills}

A game is described as a planned and organized form of play structured for the players/learners to accomplish a certain task while at the same time acquires certain skills. The use of games in teaching and learning engineering designs and other technology concepts continuously increases. This is evident in the growing number of research publications on the integration and the effectiveness of the game-based learning on students learning outcomes more particularly, the 21 st-century skills including reasoning skills [11]. Both technology and engineering classes utilize games in the form of a card, board, live-action, gamification element and digital game which are expected to make learners active participants to construct meaning and understanding of concepts.

Ertmer and Newby [12] emphasized that learning is an active and contextualized process of knowledge construction rather than acquiring. This emphasis is based on the constructivist point of view that learning is an active process that involves the 
construction of ideas or conceptual meaning on the concept as a result of experience. This ideology formed the work of John Dewey and Jean Piaget in childhood development and educational theories describing the experience as the basic source of knowledge and skills [13]. Hence, learning strategies that involve learning by doing fosters creative thinking, reasoning and problem-solving skills [14]. Game-based learning is, however, considered as one of those learning strategies that promote creativity, reasoning and problem-solving skills among engineering students [15]. Gamebased learning is a method instruction that utilizes games to guide learners to acquire a set of skills such as critical thinking, reasoning, problem-solving skills which help them achieve the specific learning objectives.

Game-based learning as an example of project-based learning is a cultural contextual form of a game that engages students through pattern stimulating, organizing and developing components' relationship which enhances their problem-solving, critical thinking and reasoning skills [16]. These games are actively engaged through various processes and steps chosen which is initiated and directed by students' curiosity, intrinsic motivation to learn and acquire reason for certain action or inaction. The major benefits of game-based learning are that it enables the learners to analyze situations, organize data and information, set a goal, define the relationship and construct different patterns and designs [17]. These skills enable learners to think, reason and construct engineering and technological design or solve mechanical problems of a machine. Industries and companies continuously get interested and engage graduates with these qualities.

\section{$4 \quad$ Methodology}

The researchers utilized systematic review format and synthesized the existing literature through search strategy, inclusion and exclusion criteria, framework analysis and quality assessment as follows:

\subsection{Search strategy}

The researchers extensively searched for available and relevant literature using keywords "reasoning skills", "reasoning skills AND game-based learning" "gamebased learning AND engineering" "game-based learning AND technology" "reasoning skills AND engineering" and "reasoning skills AND technology". The search was made using Web of Science, Scopus, Google Scholar advanced search, Willey, Tylor and Francis Libraries and Research Gate. The results of this search were 90 articles.

\subsection{Inclusion and exclusion criteria}

After the overall search, the researchers utilized inclusion and exclusion criteria based on which only empirical studies carried out on games-based learning and students' reasoning skills in engineering and technology and published from 2015 to date were considered. The reason for excluding articles published before 2015 was to ena- 
ble researchers utilized the most recent findings and the fact that similar systematic review on game-based learning generally was carried out in 2016 by Bodnar et. al. [11].

\subsection{Framework analysis}

The framework of the results from the review was tabulated using four items/elements and was used as data for analysis and discussions of findings. The items/elements are; type of game, description of the game and authors and year of publication in the form number system (see table 1.0).

\subsection{Quality Assessment}

To ensure the quality and obtain authentic and qualitative data about game-based learning and reasoning skills in engineering and technology, only complete and fulltext available articles published in the peer-reviewed journal were selected and reviewed. The journals were accessed and were mostly from the first quartile to fourth quartiles of the Web of Science and Scopus indexed.

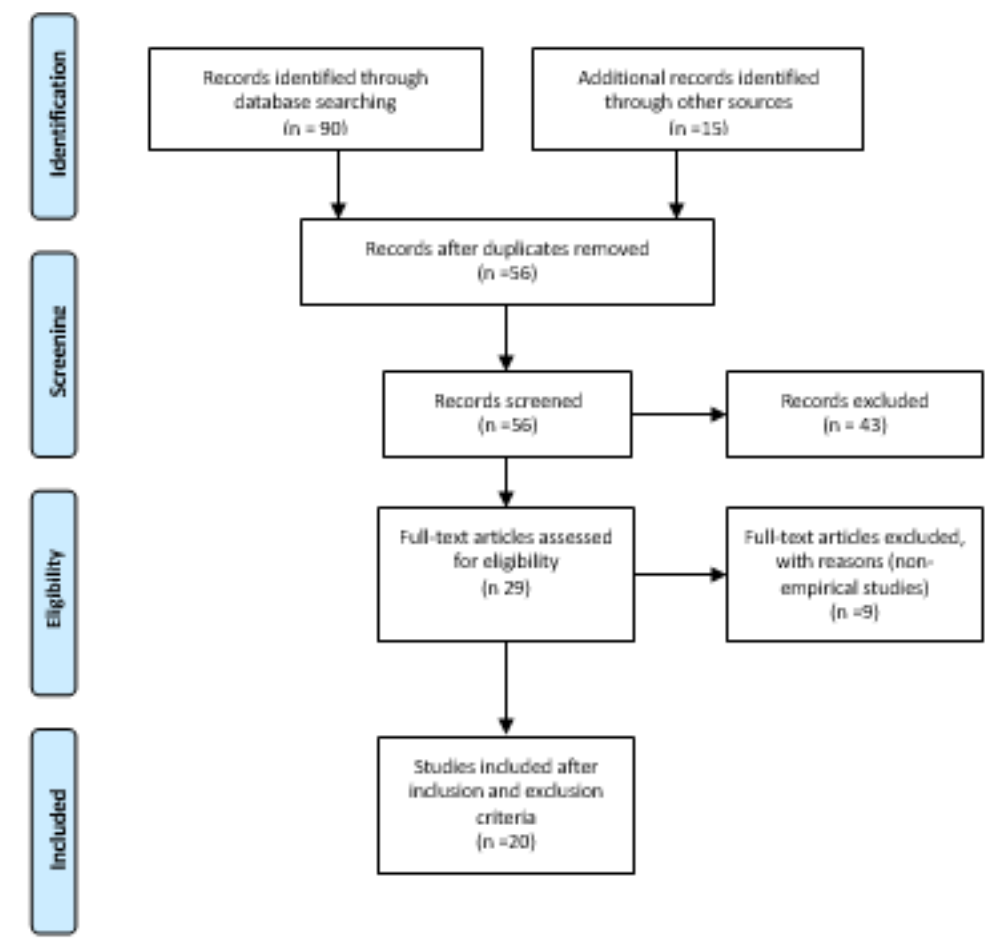

Fig. 1. Research Protocol Based on Preferred Reporting Items for Systematic Reviews and Meta-Analyses [18-19] 


\section{Results and Discussions of the Findings}

Based on the inclusion and exclusion criteria 20 articles were found suitable for inclusion into the studies.

Table 1. Results

\begin{tabular}{|c|c|c|c|}
\hline $\mathbf{S} / \mathbf{N}$ & Type of Game & Description & Authors \\
\hline 1. & Puzzle & $\begin{array}{l}\text { A normal or digital picture on wood or cardboard and } \\
\text { cut into pieces of different and various shapes that } \\
\text { could be fitted together. }\end{array}$ & {$[20],[21]$ and [22] } \\
\hline 2. & Scratch & $\begin{array}{l}\text { A visual programming software involving sound, } \\
\text { graphics and other programs }\end{array}$ & $\begin{array}{l}{[23],[24],[25] \text { and }} \\
{[26]}\end{array}$ \\
\hline 3. & Brain-Blast & $\begin{array}{l}\text { a competitive game that encourages learners to collab- } \\
\text { orate and come up with different ideas that are related } \\
\text { to a topic and show their connectivity }\end{array}$ & {$[1]$ and $[17]$} \\
\hline 4. & $\begin{array}{l}\text { Programming } \\
\text { game (Simulation) }\end{array}$ & $\begin{array}{l}\text { It is an algorithmic or mathematical model equipped } \\
\text { with an appropriate set of constraints to permit predic- } \\
\text { tive analysis of a system }\end{array}$ & $\begin{array}{l}{[27],[28],[29],[30]} \\
\text { and }[31]\end{array}$ \\
\hline 5. & Video Game & $\begin{array}{l}\text { It is an intuitive but complex system involving interac- } \\
\text { tive, media and simulation technologies that support } \\
\text { natural capabilities and creativities of the learners }\end{array}$ & $\begin{array}{l}{[32],[33],[34] \text { and }} \\
{[35]}\end{array}$ \\
\hline 6. & Kahoot & $\begin{array}{l}\text { is a game-based learning environment that makes } \\
\text { creating, sharing and playing content in the form of a } \\
\text { game to make learners engaged }\end{array}$ & [36] and [37], \\
\hline
\end{tabular}

\subsection{Relevant games that promote reasoning skills}

As indicated in table 1.0, there are varieties of games that could promote students' reasoning skills in engineering and technology which includes Scratch, Puzzle, Simulation, Video Game, Kahoot and Brain Blast. See figure 2.

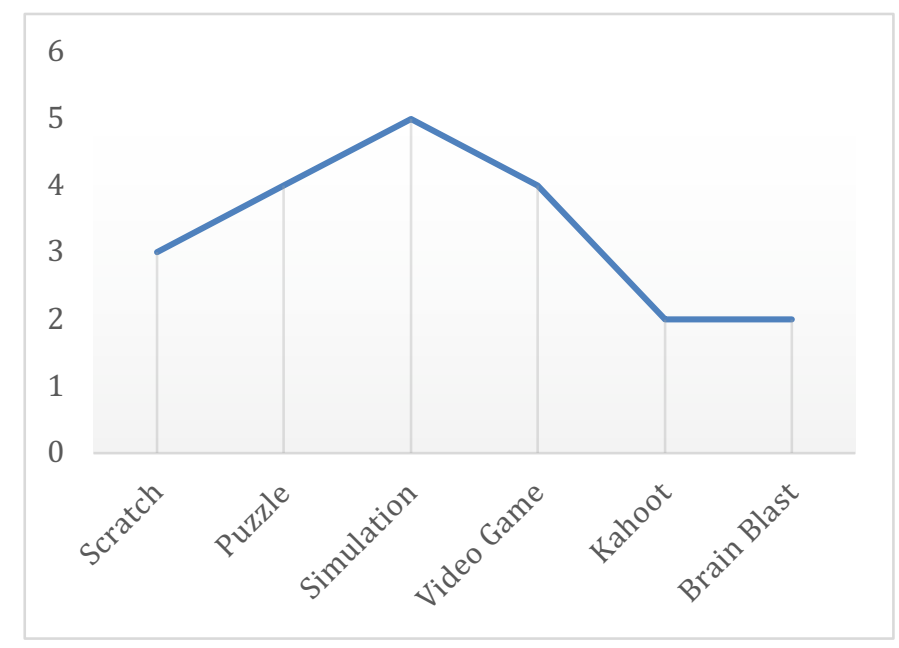

Fig. 2. Statistics of Relevant Games in Engineering and Technology 
Figure 2 above revealed that among the common games used in teaching and learning engineering and technology courses, simulation games have the highest frequency of utilization followed by puzzle and video games while Kahoot and Brain-Blast recorded least frequencies based on the reviewed empirical studies.

Scratch: As the name implies it is derived from a technique by disk jockey's scratching involving sound, graphics and other programs. The first version of this game-based project was developed in 2003 by Brian Silverman and Paula Bonta. Though there are many versions, the recent one is 3.x released in January 2019. It enables technology and engineering teachers to design and create a conceptual and visual lesson that would guide abstract concepts learning and develop students' reasoning skills. A study was carried out by Oluk and Korknaz [23] compared computational thinking of students taught using programming using scratch and those without the scratch and discovered that there is a high level of a significant relationship between students' computational thinking skills and their programming skills in scratch. Students' reasoning skills were found to be enhanced when they play with a scratch project [24-26]. Hence, integrating scratch project-based game in teaching and learning promote students' reasoning skills in computer engineering and other engineering and technology domains.

Puzzle: This is a game that comprises of a printed picture on wood or cardboard and cut into pieces of different and various shapes that could be fitted together. It may also involve a machine saw that has a fine blade that could be used to cut a curved line in a sheet of wood, plastic or metal. Playing jigsaw puzzle regularly promotes students spatial reasoning skills [21]. The game puzzle engages students' creativity, emotions, curiosity and increases their lateral and thinking skills in engineering and technology courses [20] and interacting with games in the form of puzzle enhances reasoning skills [22]. These kinds of games according to the literature are highly effective in civil engineering such as building construction which contributes to the national development.

Simulation game: It is an algorithmic or mathematical model equipped with an appropriate set of constraints to permit predictive analysis of a system [38]. The game is applied to many domains including non-engineering education. Computerized simulation games could be utilized to educate engineers and planners working with construction industries to reason before carrying out a task. Simulations games are proven as an effective strategy for promoting reasoning skills and increases learning competencies [27-28], game-based programming was more successful in teaching informatics engineering than traditional programming [29-31]. The simulation game is, therefore, applicable to various tasks and tradeoffs in civil engineering, electronic machines and power electronic circuits in electrical engineering, digital logic in computer technology and engineering system dynamics and thermodynamics in mechanical engineering etc. These domains in recent time contribute significantly to the growth and development of nations' economy.

Brain blast: This is a competitive game that encourages divergent thinking among learners. It encourages them to learners to collaborate and come up with different ideas that are related to a topic and show their connectivity. This game proved effective in teaching contents that require reasoning and creative skills for problem-solving 
and serve as a prelude for many creative projects writing [1] and [17]. Technology and engineering students may find the game interesting and fun as it engages them and to creatively think and reason for effective design and crafting innovative machines and services for national development.

Video game: This is an intuitive but complex system involving interactive, media and simulation technologies that support natural capabilities and creativities of the learners [39]. It comprises of several challenging tasks that require problem-solving and decision making through action responses [40]. Video is one of the medias that support teachers' of 21 st-century skills to innovative learning environment that enhances problem-solving, team-working and problem solving skills [41]. Although a finding revealed that game-based learning did not show any significant improvement in reasoning skills [32], it was however proved by many research findings that video game enhances reasoning skills in engineering and technology [31-33]. This is as a result of the fact that most of these games provides learners (users) with a dynamic and interactive learning environment [42]. The intuitive nature of this digital gaming makes it suitable for training in engineering design such as car and many machine designs. These kinds of mechanical designs are parts of what greatly contributes to nation' economy and overall development.

Kahoot: Kahoot is a game-based learning environment that enables creating, sharing and playing content in the form of a game to make learners engaged. It is a dynamic learning environment to motivate students to learn better. Some empirical studies revealed that learning environment enriched with Kahoot influence students' learning outcome including critical thinking and reasoning skills [34-35]. This implies that the dynamic and interactive nature of the game makes students curiosity as an agent of enhancing their reasoning skills. Hence the reasoning skills guides critical thinking, problem-solving and creativity which serves as components of 21 st-century skills necessary for national development.

\section{Conclusion}

The recent struggles of nations toward surviving and competing in the competitive economy and targets for attaining industrial revolution 4.0 goals, make it necessary for them to acquire reasoning. To achieve these targets, technology and engineering prove to play a significant role and can only perform their roles when the programs were taught in a learning environment that supports students' reasoning skills which are believed to be supported by game-based learning. It is, therefore, suggested that teachers of engineering and technology courses, should integrate game-based learning in those courses to enhance reasoning skills for better productivity. The research was limited to only empirical studies, full articles written in English and published from 2015 to date in higher indexed journals or proceedings. It is also limited to only gamebased learning on reasoning skills in engineering and technology. Further, researchers could include other non-indexed journals, articles written in languages other than English and dated beyond 2015 and from other sources and other disciplines. 


\section{$7 \quad$ Acknowledgement}

The research project was supported by European Union program ERASMUS+, Capacity building in higher education, № 73751-EPP1-2016-1-DE-EPPKA2-CBHEJP, Innovative teaching and learning strategies in open modelling and simulation environment for student-centered engineering education (InMotion) and Universiti Teknologi Malaysia (Vot 4C118). Any opinions, findings and conclusions or recommendations expressed in this publication are those of the authors and do not necessarily reflect the views of the above-mentioned organizations.

\section{References}

[1] K. Paterson, "Games That Promote Problem-Solving Skills Creative," Pembroke Publishers., 2009. [Online]. Available: https://www.stenhouse.com/sites/default/files/public/leg acy/pdfs/8247ch10.pdf. [Accessed: 14-Sep-2019].

[2] G. Barata, S. Gama, J. Jorge, and D. Goncalves, "Engaging engeneering students with gamification,” 2013 5th Int. Conf. Games Virtual Worlds Serious Appl. VS-GAMES 2013, no. September, 2013. https://doi.org/10.1109/vs-games.2013.6624228

[3] S. A. Wahab, R. C. Rose, and S. I. W. Osman, "Defining the Concepts of Technology and Technology Transfer: A Literature Analysis,” Int. Bus. Res., vol. 5, no. 1, pp. 61-71, 2011.

[4] I. Poel and R. Lamber, Ethics, Technology, and Engineering: An Introduction, vol. 112, no. 483. 1966.

[5] D. Gunay, "The Philosophy of Technology and Engineering," J. Univ. Res., vol. 1, no. 1, pp. 7-13, 2018.

[6] G. A. David and B. H. Michael, Introduction to Mechatronics and Measurement Systems. New York: McGraw-Hill, 2012.

[7] D. Kamińska, T. Sapiński, N. Aitken, A. Della Rocca, M. Barańska, and R. Wietsma, "Virtual reality as a new trend in mechanical and electrical engineering education," Open Phys., vol. 15, no. 1, pp. 936-941, 2017. https://doi.org/10.1515/phys-2017-0114

[8] J. Kojmane and A. Aboutajeddine, "Strengthening engineering design skills of first-year university students under resources constraints," Int. J. Mech. Eng. Educ., vol. 44, no. 2, pp. 148-164, 2016. https://doi.org/10.1177/0306419016641006

[9] A. Seth, J. M. Vance, and J. H. Oliver, "Virtual reality for assembly methods prototyping: A review," Virtual Real., vol. 15, no. 1, pp. 5-20, 2011. https://doi.org/10.1007/s10055009-0153-y

[10] J. Uziak and N. Fang, "Improving students' freehand sketching skills in mechanical engineering curriculum,” Int. J. Mech. Eng. Educ., vol. 46, no. 3, pp. 274-286, 2018. https:// doi.org/10.1177/0306419017744156

[11] C. A. Bodnar, D. Anastasio, J. A. Enszer, and D. D. Burkey, "Engineers at Play: Games as Teaching Tools for Undergraduate Engineering Students," J. Eng. Educ., vol. 105, no. 1, pp. 147-200, 2016. https://doi.org/10.1002/jee.20106

[12] P. A. Ertmer and T. J. Newby, "Ertmer2008.Pdf," Performance Improvement Quarterly, vol. 6, no. 4. pp. 50-72, 1993.

[13] J. C. Chen, "Theoretical Bases for Using Virtual Reality in Education," Themes Sci. Technol. Educ. Spec. issue, vol. Special Is, pp. 71-90, 2009.

[14] K. Nordstrom and P. Korpelainen, "Creativity and inspiration for problem solving in engineering education,” Teach. High. Educ., vol. 16, no. 4, pp. 439-450, 2011. 
[15] M. Puteh and M. M. Ismail, "Project-based Engineering Design Education: A Malaysian Case,” Eur. J. Soc. Sci., vol. 16, no. 13, pp. 411-419, 2010.

[16] S. Johnson, Everything bad is good for you: How today's popular culture is actually making us smarter. New York: Riverhead Books/Penguin Putnam, 2005. https://doi.org/10.11 11/j.1540-5931.2006.00343.x

[17] E. A. Lasley, "Twenty-first Century Literacy , Game-based Learning , Project-based Learning," J. Lit. Technol., vol. 18, no. 3, 2017.

[18] D. Moher et al., "Preferred reporting items for systematic review and meta-analysis protocols (PRISMA-P) 2015 statement,” Rev. Esp. Nutr. Humana y Diet., vol. 20, no. 2, pp. 148-160, 2016.

[19] D. Moher, A. Liberati, J. Tetzlaff, and D. G. Altman, "Preferred Reporting Items for Systematic Reviews and Meta- Analyses: The PRISMA Statement," The PRISMA Statement, 2009. [Online]. Available: www.prisma-statement.org. [Accessed: 22-Sep-2019]. https:// doi.org/10.1136/bmj.b2535

[20] N. Falkner, R. Sooriamurthi, and Z. Michalewicz, "Puzzle-based learning for engineering and computer science," Computer (Long. Beach. Calif)., vol. 43, no. 4, pp. 20-28, 2010. https://doi.org/10.1109/mc.2010.113

[21] S. Klymchuk, "Puzzle-based learning in engineering mathematics: students' attitudes," Int. J. Math. Educ. Sci. Technol., vol. 48, no. 7, pp. 1106-1119, 2017.

[22] W. Wang, A. H. Tan, and L. N. Teow, "Semantic Memory Modeling and Memory Interaction in Learning Agents," IEEE Trans. Syst. Man, Cybern. Syst., vol. 47, no. 11, pp. 28822895, 2017. https://doi.org/10.1109/tsmc.2016.2531683

[23] A. Oluk and O. Korknaz, "Comparing Students' Scratch Skills with Their Computational Thinking Skills in Terms of Different Variables," Int. J. Mod. Educ. Comput. Sci., vol. 8, no. 11, pp. 1-7, 2016.

[24] Vaca-Cardenas et al., "Coding with Scratch: The design of an educational setting for Elementary pre-service teachers," Proc. 2015 Int. Conf. Interact. Collab. Learn. ICL 2015, no. September, pp. 1171-1177, 2015.

[25] P. R. Brown, "Work in progress: From scratch-the design of a first-year engineering programming course," ASEE Annu. Conf. Expo. Conf. Proc., vol. 2017-June, 2017.

[26] F. Kalelioglu and Y. Gulbahar, "The effects of teaching programming via Scratch on problem solving skills: A discussion from learners' perspective," Informatics Educ., vol. 13, no. 1, pp. 33-50, 2015.

[27] S. Saravanan and S. D. Juliet, "Education Through Technical Games," Proc. 2018 2nd Int. Conf. Adv. Electron. Comput. Commun. ICAECC 2018, pp. 1-5, 2018.

[28] W. G. Junior, "Applying design cognition in a game-based learning context to develop entrepreneurial competencies," in Proceedings of the European Conference on Games-based Learning 12th European Conference on Game Based Learning, ECGBL 2018; SKEMA Business, 2018, pp. 773-779.

[29] G. Kiss and Z. Arki, "The Influence of Game-based Programming Education on the Algorithmic Thinking,” Procedia - Soc. Behav. Sci., vol. 237, no. June 2016, pp. 613-617, 2017. https://doi.org/10.1016/j.sbspro.2017.02.020

[30] A. J. Magana and G. Silva Coutinho, "Modeling and simulation practices for a computational thinking-enabled engineering workforce," Comput. Appl. Eng. Educ., vol. 25, no. 1, pp. 62-78, 2017. https://doi.org/10.1002/cae.21779

[31] Y. Li, Z. Huang, M. Jiang, and T. Chang, "The Effect on Pupils' Science Performance and Problem-Solving Ability through Lego: An Engineering Design-based Modeling Approach,” Educ. Technol. Soc. 19 Issue 3 Pages Spec. Issue SI, vol. 19, no. 3, pp. 143-156, 2016. 
[32] E. B. Walker, "Opportunities for Innovation: Game-based Learning in an Engineering Senior Design Course," ProQuest Diss. Theses, p. 174, 2016.

[33] A. U. Gold et al., "Spatial skills in undergraduate students-Influence of gender, motivation, academic training, and childhood play," Geosphere, vol. 14, no. 2, pp. 668-683, 2018. https://doi.org/10.1130/ges01494.1

[34] S. H. Ye, T. Y. Hsiao, and C. T. Sun, "Using commercial video games in flipped classrooms to support physical concept construction," J. Comput. Assist. Learn., vol. 34, no. 5, pp. 602-614, 2018. https://doi.org/10.1111/jcal.12267

[35] C. Politowski, D. De Vargas, L. M. Fontoura, and A. Foletto, "Software Engineering Processes in Game Development: a Survey about Developers' Experiences," in Proceedings of SBGames 2016, 2016, pp. 154-161.

[36] E. Rodríguez-Rodríguez et al., "The Tool Kahoot as Methodological Strategy to Encourage the Participation and Active Learning of University Students," in 10th International Conference of Education, Research and Innovation, 2017, pp. 644-650.

[37] S. A. Licorish, H. E. Owen, B. Daniel, and J. L. George, "Students' perception of Kahoot!'s influence on teaching and learning," Res. Pract. Technol. Enhanc. Learn., vol. 13, no. 1,2018 . https://doi.org/10.1186/s41039-018-0078-8

[38] A. A. Deshpande and S. H. Huang, "Simulation games in engineering education: A stateof-the-art review," Comput. Appl. Eng. Educ., vol. 19, no. 3, pp. 399-410, 2011. https:// doi.org/10.1002/cae.20323

[39] Z. Kosmadoudi, T. Lim, J. Ritchie, S. Louchart, Y. Liu, and R. Sung, "Engineering design using game-enhanced CAD: The potential to augment the user experience with game elements," CAD Comput. Aided Des., vol. 45, no. 3, pp. 777-795, 2013. https://doi.org/10.10 $\underline{16 / j . c a d .2012 .08 .001}$

[40] C. Lindley, "Game Taxonomies: A High Level Framework for Game Analysis and Design,” 2003. [Online]. Available: www.gamasutra.com/features/20031003/lindley_01.shtm 1. [Accessed: 14-Sep-2019].

[41] H. Mohamed, A. Saidalvi, and N. A. Tashiron, "Project Based Learning in Flipped Classroom Based on Student' s Cognitive Style,” Int. J. Recent Technol. Eng., vol. 7, no. 6S3, pp. 696-700, 2019.

[42] F. Aliyu and C. A. Talib, "Virtual Chemistry Laboratory: A Panacea to Problems of Conducting Chemistry Practical at Science Secondary Schools in Nigeria," Int. J. Eng. Adv. Technol., vol. 8, no. 5C, pp. 544-549, Sep. 2019. https://doi.org/10.35940/ijeat.e1079.058 $\underline{5 \mathrm{c} 19}$

\section{Authors}

Corrienna Abdul Talib is currently the Senior Lecturer of Department of Educational Science, Mathematics and Creative Multimedia, Universiti Teknologi Malaysia (UTM). She is a lecturer in the area of Chemistry and Technology in Chemistry Education. She obtained her PhD from Universiti Sains Malaysia in the field of chemistry education. Prior to joining UTM, she was the science specialist of R\&D division at Southeast Asian Ministers of Education Organisation Regional Centre for Education in Science and Mathematics (SEAMEO RECSAM), which role included leading research and training educators from Southeast Asian countries. Before that, she had 11 years of experience as science and chemistry secondary school teachers. 
Faruku Aliyu is currently a $\mathrm{PhD}$ student in the Department of Educational Science, Mathematics and Creative Multimedia, School of Education, Universiti Teknologi, Malaysia. Also interested in technology-based instruction in chemistry. He is a lecturer in the Department of Science Education, Faculty of Education, Sokoto State University, Sokoto, Nigeria. faruk.aliyu@ssu.edu.ng

Adi Maimun bin Abdul Malik is currently a Professor of Naval Architecture at the School of Mechanical Engineering, Universiti Teknologi Malaysia (UTM). He has more than 30 years of teaching experience in university and specializes in the field of marine structures dynamics, simulations, and hydrodynamic experiments. He also actively involves in engineering education and led as coordinator in several ERASMUS+ funding programs in UTM. adi@utm.my

Kang Hooi Siang is currently the Director of the Marine Technology Center in Universiti Teknologi Malaysia (UTM). He obtained his Ph.D. from Texas A\&M University in the field of ocean engineering. He served at an oil company and professional engineering consultancy firm and involved in several deepwater oil and gas development projects. He also actively involved in engineering education by joining several ERASMUS+ funding programs and ASEE conferences. kanghs@utm.my

Article submitted 2019-10-03. Resubmitted 2019-10-29. Final acceptance 2019-11-02. Final version published as submitted by the authors. 